\title{
A INFLUÊNCIA DA CONCENTRAÇÃO SÉRICA DE IgG E DIFERENTES PROTOCOLOS DE ALEITAMENTO NO GANHO DE PESO DE NOVILHAS HOLANDESAS
}

\section{(The influence of the concentration of IgG serum and different suckling protocols in the weight gain of holstein heifers)}

\author{
Juliandro Ostapechen, Ana Alix Mendes de Almeida Oliveira, Patricia Barcellos Costa, \\ Suzana da Cruz Pires, Ilton Isandro Eckstein ${ }^{1}$ \\ 1 Correspondência: eckstein@zootecnista.com.br
}

RESUMO: Com o objetivo de se avaliar a influência da concentração sérica de lgG no ganho de peso de bezerras em fase de aleitamento e após um ano de vida, 45 bezerras Holandesas foram distribuídas em três baias coletivas com alimentadores automáticos e submetidas a três protocolos de aleitamento (Tratamentos experimentais) denominados de $4 \mathrm{~L}$, que teve o fornecimento de quatro litros diários de sucedâneo lácteo; $6 \mathrm{~L}$, com seis litros; e $\mathrm{AL}$, com fornecimento ad libitum. As bezerras entraram no experimento com cinco dias de idade e concentração de IgG que variou entre 13,4 e $43,7 \mathrm{mg} / \mathrm{dL}$. O peso foi aferido semanalmente. Após o desmame todas as bezerras foram manejadas sob as mesmas condições até um ano de vida. Nessa fase, a mensuração do peso corporal foi feita mensalmente. Utilizou-se o delineamento inteiramente casualizado, correlação linear de Pearson, análise de variância ANOVA e testes de Tukey, e t pareado a 5\%. Não houve influência da IgG no ganho de peso ao desmame e também após um ano, entre os tratamentos e desconsiderando-se os tratamentos. Quanto aos protocolos de aleitamento, os tratamentos $6 \mathrm{~L}$ e $\mathrm{AL}$ foram superiores no ganho de peso ao desmame, enquanto 4L e ALforam superiores após um ano.

Palavras-chave: aleitamento, bezerras; desempenho; IgG; imunidade

\begin{abstract}
Aiming the evaluation of the influence of $\lg G$ serum concentration in the weight gain of heifers, during suckling and after their first year of life, 45 Holstein heifers were distributed in three collective stalls, equipped with automatic feeders, where they were submitted to three different suckling protocols (experimental treatments) called $4 \mathrm{~L}$, with a daily provision of four liters of milk replacer; 6L, with six liters; and AL, with ad libitum provision. The heifers entered the experiment on their fifth day of life with IgG concentration ranging between 13.4 and $43.7 \mathrm{mg} / \mathrm{dL}$. The heifers' weight was measured weekly. After weaning, the heifers were managed under the same conditions until they were one year old. At this stage, the measurement of the body weight was taken monthly.It was used a completely randomized design, Pearson's linear correlation, analysis of ANOVA variance, Tukey's test and a paired t-test at 5\%. There was no influence of IgG in the weight gain at weaning or after one year, between treatments and disregarding the treatments. Concerning the feeding protocols, $6 \mathrm{~L}$ and $A L$ treatments were higher in the weight gain to weaning, while $4 \mathrm{~L}$ and $A L$ were higher after one year.
\end{abstract}

Key Words: suckling, heifers; performance; IgG; immunity 


\section{INTRODUÇÃO}

A criação eficiente das bezerras em seu período inicial, que compreende do nascimento a desmama, tem importância fundamental para a produtividade futura da matriz leiteira, tendo eficiência produtiva diretamente proporcional ao bom desenvolvimento e estado sanitário (LOPES e VIEIRA, 1998). Neste contexto, um dos maiores desafios para o bom desenvolvimento das matrizes de reposição na atividade leiteira é proporcionar 0 rápido crescimento, associado ao adequado estado sanitário e a um valor financeiro compatível. Em se tratando de eficiência, a nutrição adequada, a sanidade e o bem-estar, são os esteios para garantirem o bom resultado em todo o período da recria dos bovinos leiteiros, sobretudo no início do processo (DACCARETT et al.,1993).

O colostro, através da passagem de imunoglobulinas, tem a responsabilidade de proporcionar a proteção imunológica nos primeiros dias de vida, até que o mesmo desenvolva a capacidade de produzir células de defesa por si mesmo (MENDONSA, 2011). A concentração de IgG circulante oriunda da transferência de imunidade passiva adquirida pela ingestão de colostro figura como um fator que acarreta diferentes competências imunológicas às bezerras (BORDERAS et al., 2009).

Ballou (2012) reportou que tratamentos com maiores quantidades de sucedâneo lácteo fornecido para bezerras, proporcionaram maior ingestão de glicose e apresentaram melhor resposta imunológica após o desmame aos 77 dias em infecção induzida experimentalmente, não havendo diferença nas semanas iniciais. Por outro lado, segundo Nonnecke et al. (2003) e Foote et al. (2005) a influência da quantidade de leite ingerida na eficiência imune das bezerras leiteiras ainda não foi bem entendida pois a quantificação da eficiência do estado sanitário das bezerras é subjetiva. Pode-se interpretar, portanto, que se o desempenho em ganho de peso for satisfatório, a imunidade também será adequada (GOOF, 2006).

Sendo assim, o presente estudo tem como objetivos verificar a influência da concentração de IgG sobre 0 desempenho das bezerras em fase de aleitamento e após um ano de vida submetidas a diferentes protocolos de aleitamento, em sistema de lotes coletivos com alimentador automático. A influência do peso ao nascimento sobre a concentração de IgG sérica também será alvo de estudo. $O$ resultado em ganho de peso ao desmame e após um ano de idade considerando-se apenas os diferentes protocolos de aleitamento, será estudado buscando-se determinar o melhor protocolo em desempenho, dentre os testados.

\section{MATERIAL E MÉTODOS}

O trabalho foi desenvolvido utilizando-se de 45 bezerras Holandesas provenientes de fazendas leiteiras do extremo Oeste do Estado do Paraná. A idade inicial das bezerras variou entre 4 e 7 dias de vida e os peso médio de 40 $( \pm 3) \mathrm{Kg}$.

As bezerras foram alojadas em baias coletivas de $54 \mathrm{~m} 2$ sendo $25 \mathrm{~m} 2$ de cama de feno para acomodação. Durante o dia as bezerras tinham livre acesso a piquetes (200 m2 de área) com grama Tifton para exposição ao sol.

As bezerras foram divididas aleatoriamente em três grupos experimentais com 15 animais cada. Os animais do tratamento $4 \mathrm{~L}$ receberam 4 litros de sucedâneo lácteo por dia. Os animais do tratamento $6 \mathrm{~L}$ receberam 6 litros de sucedâneo lácteo por dia e, os animais do tratamento $A L$ receberam sucedâneo lácteo ad libitum. As refeições compreendiam um intervalo de tempo mínimo de 120 minutos entre elas, num total de até 12 refeições diárias. 
Todos os animais receberam concentrado ad libitum.

O sucedâneo lácteo foi composto por $22 \%$ de proteína; $20 \%$ de gordura; e $45 \%$ de lactose. O concentrado possuía $21 \%$ de proteína bruta, 3,5\% de gordura e $45 \%$ de carboidratos não fibrosos. Houve consumo mínimo de grama nos piquetes de exposição ao sol, esperado para o desenvolvimento do rúmen das bezerras, porém, não foi possível mensurar a quantidade ingerida. $O$ sucedâneo lácteo e o concentrado foram fornecidos em alimentador automático.

$\mathrm{Na}$ entrada das bezerras para o experimento, aconteceu a coleta de soro sanguíneo para mensuração de concentração de imunoglobulinas $G$ (lgG). A mensuração foi realizada no Laboratório de Imunologia da Universidade Federal de Minas Gerais, por meio da metodologia de imunodifusão radial, de acordo com metodologia descrita por Ameri e Wikerson (2008).

Semanalmente as bezerras foram pesadas em uma balança eletrônica. As bezerras não passaram por período de jejum pré-pesagem, pois poderia interferir nos objetivos da pesquisa, dessa forma, convencionou-se pesar todos os animais sempre no mesmo horário do dia e na mesma ordem de pesagem.

Todas as ocasiões em que as bezerras apresentaram alteração de escore fecal a temperatura retal foi aferida, para diagnosticar possíveis casos de diarreia de origem infecciosa. Em casos de alteração da temperatura retal, protocolos medicamentosos seriam administrados.

Os três tratamentos foram conduzidos com a dieta de aleitamento por 55 dias. Após esse período, realizouse o desmame com a redução gradativa de $15 \%$ do volume do leite fornecido por dia, o fornecimento de leite foi finalizado seis dias após o início do desmame. Os dados para análise estatística da fase de aleitamento foram coletados até $055^{\circ}$ dia do experimento.

Após o desmame, todas as bezerras foram agrupadas em um mesmo lote e foram alojadas em piquetes de grama Tifton 85 ad libitum. Diariamente cada animal recebeu $2 \mathrm{Kg}$ de concentrado ao dia até completar um ano de idade e suplemento mineral ad libitum. Nos piquetes havia livre acesso à bebedouro e comedouros de alvenaria cobertos. Mensalmente as bezerras eram pesadas em balança convencional, até o $12^{\circ}$ mês de vida.

O delineamento experimental utilizado foi inteiramente casualizado (DIC) com 15 repetições e empregou-se o coeficiente de correlação linear de Pearson para averiguar a interdependência entre a concentração sérica de lgG, o ganho de peso médio diário no desmame (GPD desmame) e o ganho de peso médio diário a um ano de idade (GPD a um ano). Todas as médias encontradas foram submetidas a análise de variância (ANOVA) e, posteriormente, ao teste de Tukey e ao teste t pareado, ambos a 5\% de nível de significância.

\section{RESULTADOS E DISCUSSÃO}

As bezerras utilizadas no presente experimento atenderam o que a literatura científica preconiza como resultado mínimo em concentração de lgG sérica, ou seja, valor superior a $10 \mathrm{mg} / \mathrm{dL}$ de soro sanguíneo (QUIGLEY e DREWRY, 1998).

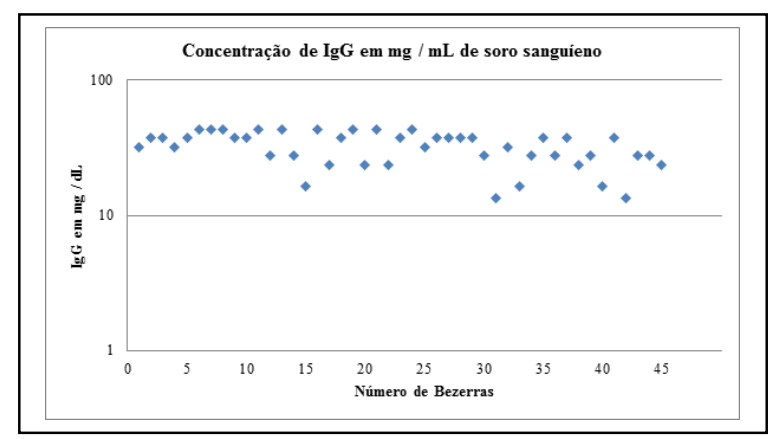


Figura 1 - Dispersão das unidades experimentais quanto à concentração de IgG sérica de bezerras com uma semana da vida, tendo como referência a concentração de $10 \mathrm{mg} / \mathrm{dL}$ de soro sanguíneo.

Através da metodologia analítica de correlação linear de Pearson, a influência da concentração sérica de $\lg G$ sobre o GPD do aleitamento e GPD a um ano foi avaliada e nenhuma diferença significativa foi encontrada, considerando-se todas as unidades experimentais independentemente de qual protocolo de aleitamento estava sendo efetuado. Quando se avaliou a concentração sérica de $\operatorname{lgG}$ em cada um dos tratamentos, também não houve diferença significativa (Tabela 1).

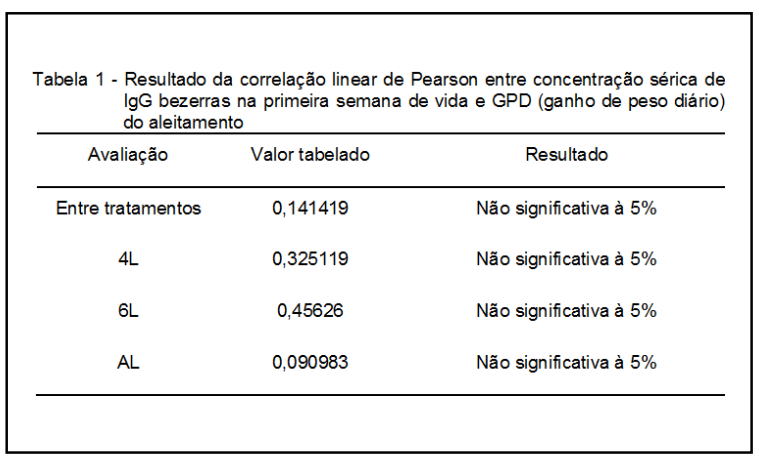

Em pesquisa realizada por Robison et al. (1988) foi evidenciada influência significativa da concentração de IgG sobre o ganho de peso das bezerras nas primeiras semanas de vida, porém, as bezerras que tiveram menor peso apresentavam concentração de IgG sérica menor do que $10 \mathrm{mg} / \mathrm{dL}$, valores esses que não ocorreram no presente estudo. A variação de $\lg G$ sérica obedeceu o intervalo de 13,7 a 43,7 $\mathrm{mg} / \mathrm{dL}$ e, nesse universo não foi encontrada influência sobre o ganho de peso. No experimento citado acima, as bezerras que apresentaram sinais clínicos com confirmação de quadro infeccioso foram descartadas e, de forma semelhante, as bezerras que eventualmente apresentassem hipertermia associada a demais sinais clínicos de diarreia e pneumonia, também seriam descartadas no atual estudo. Essa realidade reforça o fato de que na ausência de quadros infecciosos, a concentração de $\lg G$ sérica não afeta o ganho de peso diário das bezerras durante a fase de aleitamento, se ela obedecer o nível mínimo de $10 \mathrm{mg} / \mathrm{dL}$ (TYLER et al., 1996).

Com o objetivo de avaliar se o peso ao nascimento poderia ter influenciado de alguma maneira na transferência de imunidade passiva, quantificada através da concentração de IgG sérica, essa variável foi estudada. $O$ resultado encontrado mostra que não houve influência do peso ao nascimento sobre a concentração de $\lg G$ (Tabela 2).

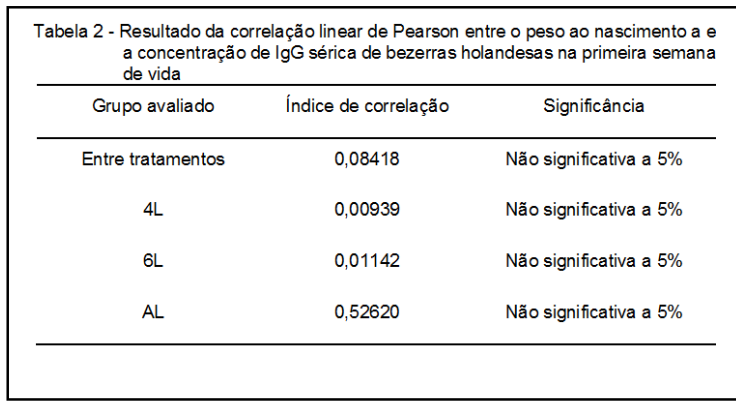

De forma semelhante ao peso ao nascimento, 0 peso ao desmame também foi mensurado e, o resultado encontrado também não apresentou diferença significativa (Tabela 3). Caso não houvesse correlação positiva entre $\operatorname{lgG}$ e GPD do aleitamento e, os maiores pesos ao desmame fossem em bezerras com as maiores IgGs, poder-se-ia admitir que 0 peso ao nascimento poderia influenciar de maneira positiva na absorção de lgG e que, um maior peso ao nascimento associado à níveis maiores de IgG poderiam refletir em maior peso ao desmame, mesmo sem se observar essa influência sobre o GPD do aleitamento. 


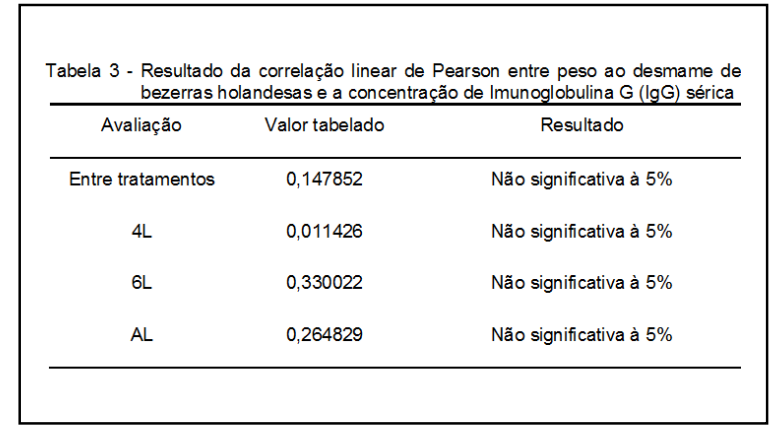

O ganho de peso a um ano de idade pode ser um indicativo do estado sanitário das novilhas, nos casos em que houver baixo desempenho (FREITAS et al., 2010). Dessa forma, se avaliou a influência do indicador de saúde das fases iniciais da vida da bezerra sobre o GPD a um ano, e o resultado na metodologia de correlação linear de Pearson foi negativo (Tabela 4). De forma semelhante ao período de aleitamento que também não teve influência da concentração de $\lg G$ ao nascimento, a um ano de idade esse perfil se repetiu. É preciso considerar que a concentração de $\operatorname{lgG}$ configura resposta imunológica passiva ao passo que com algumas semanas de idade de idade essa resposta passa a ser ativa. Essa alteração significa que o a jovem bezerra passa a produzir eficientemente suas células e glicoproteínas de defesa (TIZARD, 1998).

Admite-se que a competência imunológica com um ano de idade já está plenamente ativa e, que a concentração sérica de lgG na primeira semana de vida é reflexo do perfil imunológico passivo. Desse modo é pertinente que a concentração de lgG inicial não influencie o ganho de peso médio diário no primeiro ano de vida. Influência positiva dessa natureza poderia ter indicado que problemas sanitários que eventualmente acontecessem nas primeiras semanas de vida por uma eventual baixa concentração de $\lg G$ pudessem ter refletido no desempenho ao primeiro ano de idade, mas essa hipótese não aconteceu.

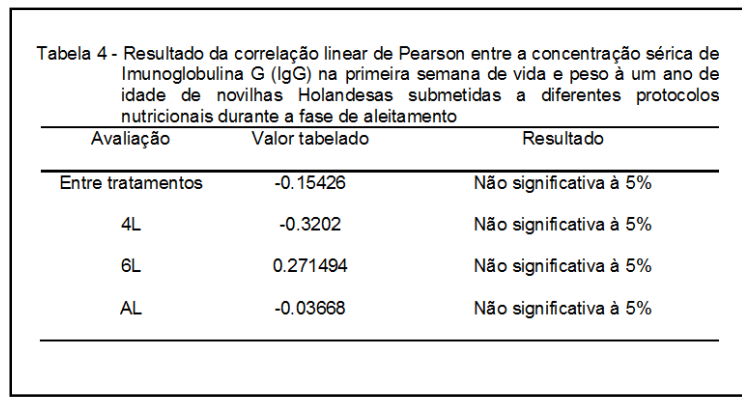

Conforme Goff et al. (2006), se o ganho de peso está sendo alcançado em níveis satisfatórios para o padrão da raça, se admite que 0 estado imunológico esteja bom. Em se tratando de bezerras que tiveram transferência de imunidade passiva (TIP) adequada, ou seja, apresentaram concentração de IgG sérica superior a $10 \mathrm{mg} / \mathrm{dL}$ e ausência de quadros infecciosos durante seu primeiro ano de vida, é pertinente que o resultado encontrado não seja significativo.

Ao correlacionar o GPD do aleitamento com o GPD do primeiro ano de vida, tem-se correlação negativa entre todos os tratamentos, exceto em $6 \mathrm{~L}$, que apresentou resultado positivo e alta correlação (Tabela 5).

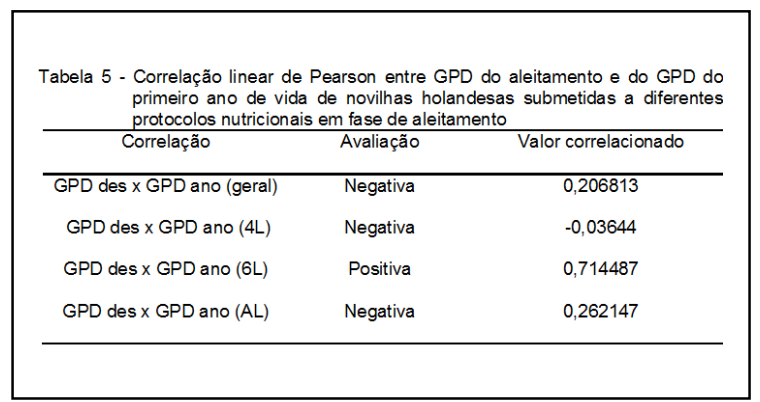

A correlação positiva em 6L permite o entendimento de que a variação entre as médias avaliadas foi semelhante. Essa análise, porém, não permite afirmar que a eficiência de $6 \mathrm{~L}$ superou os demais nem tampouco concluir que esse resultado é o que se esperava quanto ao 
ganho de peso de toda a fase de recria das novilhas.

Nos tratamentos em que 0 comportamento de variação das médias não apresentou correlação positiva, a influência do perfil dos protocolos de aleitamento pode ter resultado em diferentes comportamentos de GPD nos dois momentos avaliados. Entendendo que a correlação de $4 \mathrm{~L}$ e $\mathrm{AL}$ foram negativas, justamente os tratamentos com menor e maior ingestão de leite respectivamente, pode-se associar o que reportam Baldwin et al. (2004) em seus estudos que dizem que a dieta da fase de aleitamento influencia a transformação do animal de pré-ruminante para ruminante, com relação ao tempo em dias de vida que esse processo será concluído. Se existe variação no tempo em que o indivíduo levará para ter seu sistema digestivo em pleno funcionamento e, que esse tempo varia conforme a dieta da fase de aleitamento, é pertinente que as dietas dos extremos de fornecimento de sucedâneo lácteo, maior e menor volume, apresentem também variações de comportamento de ganho de peso que, na correlação linear de Pearson, não apresentaram positividade ao longo de todo o primeiro ano de vida.

Para avaliar as médias encontradas na correlação de Pearson, 0 teste $t$ de Student pareado foi aplicado e, observou-se que não existe significância estatística suficiente que indique que 0 GPD do aleitamento e o GPD do primeiro ano de vida foram diferentes em nenhum dos tratamentos estudados (Tabela 6).

\begin{tabular}{|c|c|c|c|}
\hline \multicolumn{4}{|c|}{$\begin{array}{l}\text { Tabela } 6 \text { - Teste t pareado entre GPD do aleitamento e GPD do primeiro ano de vida } \\
\text { de novilhas holandesas submetidas a diferentes protocolos nutricionais na } \\
\text { fase de aleitamento }\end{array}$} \\
\hline Tratamentos & Valor $t$ calculado & Valor $t$ tabelado & Avaliação \\
\hline $4 \mathrm{~L}$ & $-6,51$ & 1,77 & Não signific ativo a $5 \%$ \\
\hline $6 \mathrm{~L}$ & $-6,27$ & 2,82 & Não significativo a $5 \%$ \\
\hline AL & $-4,78$ & 2,71 & Não significativo a $5 \%$ \\
\hline
\end{tabular}

O teste t pareado evidencia que embora os valores de GPD amostrados para cada tratamento tenham variado ao longo do período de análise (no aleitamento e após um ano), estatisticamente não há evidência suficiente que comprove disparidades, ao nível de significância de $5 \%$, pois os resultados obtidos dos GPD aleitamento e GPD a um ano dentro do mesmo tratamento, se mantiveram na região de não rejeição da hipótese nula. Essa informação indica que as médias de GPD avaliadas no aleitamento e após um ano de vida não foram diferentes, considerando os tratamentos individualmente.

Ao se analisar o resultado de GPD ao aleitamento entre os tratamentos, houve eficiência de $6 \mathrm{~L}$ e $A L$ sobre $4 \mathrm{~L}$, de acordo com o teste de médias Tukey a $5 \%$ (Tabela 7).

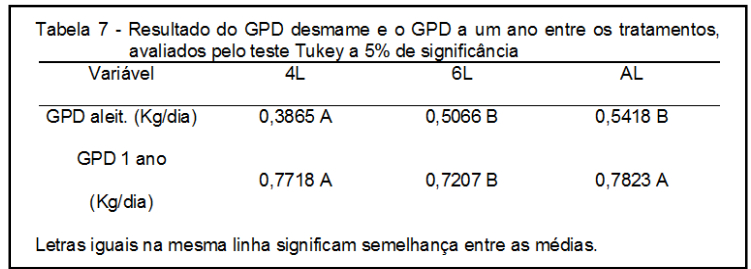

Roth et al.(2009) ofereceram maiores quantidades de concentrado em um dos tratamentos de sua pesquisa, concomitantemente ao consumo de sucedâneo lácteo restrito a $0,44 \mathrm{Kg}$ matéria seca (MS) por dia. A busca pelo desmame precoce da bezerra, com o objetivo de se obter maior consumo de alimento sólido, foi o que pautou esse estudo. $O$ resultado obtido no tratamento com menor ingestão de leite resultou em menor ganho de peso, que vem de encontro ao resultado encontrado no presente trabalho em 4L.

De acordo com Appleby et al. (2001), o volume de leite ou sucedâneo lácteo que se recomenda oferecer às bezerras, sobretudo no primeiro mês de vida, deve ser de no mínimo $10 \%$ do peso vivo ao 
dia. O consumo restrito a $10 \%$ do volume se comparado com ingestão espontânea que pode chegar a até $20 \%$ do peso vivo em leite, apresenta eficiência menor (KHAN et. al., 2007). Ao considerar o peso médio das bezerras e a ingestão proporcional de leite, ao final dos primeiros 30 dias de experimento, as bezerras do 4L estavam abaixo do mínimo que se recomenda para essa fase (Tabela 8). Esse fato justifica 0 resultado inferior em GPD do aleitamento de $4 \mathrm{~L}$ em comparação com os $6 \mathrm{~L}$ e $\mathrm{AL}$, que entre si não apresentaram diferença.

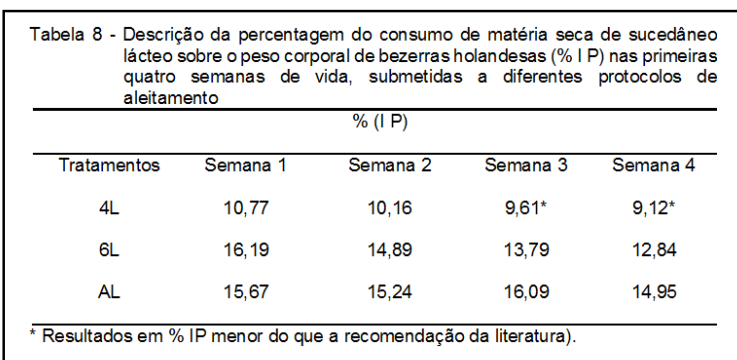

O resultado de $4 \mathrm{~L}$ é condizente com o que foi reportado por Hill et al. (2010), no qual o tratamento com menor ingestão de leite, $(0,44 \mathrm{Kg}$ de ingestão de matéria seca por dia), teve menor desempenho em ganho de peso, do que os demais tratamentos que ingeriram quantidades maiores desse alimento. Por outro lado, a quantidade de concentrado ingerida por $4 \mathrm{~L}$ durante a fase de aleitamento $(0,76 \mathrm{Kg} /$ dia para $\mathrm{T} 1$; $0,699 \mathrm{Kg} /$ dia para $\mathrm{T} 2 ; 0,301 \mathrm{Kg} /$ dia para T3) pode ter acelerado o desenvolvimento do rumem, que pode ter aumentado a eficiência desse lote no pós desmame, equiparando o resultado desse tratamento aos demais, nas fases seguintes.

É importante considerar-se que a ingestão precoce de concentrado resulta em produção de ácidos graxos voláteis, que estimulam de maneira direta 0 desenvolvimento das papilas ruminais e, da parede ruminal (GREENWOOD et al. 1997). Kristensen et al. (2007) reportam que o tratamento com menor quantidade de leite ingerido foi o que apresentou maior desenvolvimento ruminal. Tanto a maior ingestão de concentrado quanto a menor ingestão de leite, foram características apresentados por $4 \mathrm{~L}$ e que condizem com seu desempenho, que foi inferior aos demais no GPD do aleitamento, mas que apresentou 0 melhor desempenho no GPD do primeiro ano de vida, possivelmente por ter se tornado ruminante em menor tempo que os demais tratamentos.

É preciso considerar que fisiologicamente, no primeiro mês de vida das bezerras leiteiras, a competência digestiva, relacionada diretamente à produção enzimática, está pautada na digestão de leite e nutrientes derivados do mesmo. De acordo com Guilloteau et al. (1985) a secreção de amilase necessária para a digestão de alimentos de origem vegetal, começa a ser produzida ao longo do tempo e na medida que a ingestão de amido se intensifica. Entendendo essa realidade, considera-se de importância fundamental o atendimento da ingestão de leite sobre o peso da bezerra, sobretudo nas primeiras semanas de vida, pois eventuais compensações nutricionais resultam em aumento de ingestão de alimentos sólidos, podem não resultar na eficiência nutricional suficiente para manter 0 desenvolvimento pleno da bezerra em ganho de peso nessa fase (VAN AMBURG, 2003).

$A$ vantagem em ganho de peso no aleitamento apresentada por $\mathrm{AL}$ e $6 \mathrm{~L}$, possibilita uma análise muito semelhante ao que Hill et al. (2010) relataram em seu experimento. No referido trabalho, o tratamento que teve maior ingestão de leite também apresentou maior GPD ao desmame, porém nas primeiras semanas após o desmame, o resultado de GPD do lote que havia ingerido quantidades maiores de leite durante 0 aleitamento, foi pior em comparação com os tratamentos que haviam ingerido 
quantidades menores de leite. Esse dado é condizente com Kristensen et al. (2007) que reporta que volumes maiores de leite resultaram em desenvolvimento ruminal mais tardio do que os tratamentos com menor quantidade de leite.

Ao longo do tempo de avaliação que no presente trabalho foi de 12 meses e que, no trabalho de Hill et al. (2010) foi de apenas três meses, se teve o resultado de GPD do primeiro ano de vida superior para $A L$ em comparação com $6 \mathrm{~L}$ e equivalente a $4 \mathrm{~L}$. Esse dado indica que, mesmo havendo uma possível demora para atingir a plenitude das funções ruminais, o AL apresentou eficiência otimizada de GPD do primeiro ano de vida.

Por outro lado, a diferença do AL sobre $6 \mathrm{~L}$ no GPD do primeiro ano, pode ter ocorrido por duas razões. A primeira delas porque não teve a maior ingestão de leite, que acarretaria um desempenho diferenciado na fase de aleitamento, considerando-se que não houve diferença entre $6 \mathrm{~L}$ e $A L$ nessa fase, mas o consumo de sucedâneo lácteo de $6 \mathrm{~L}$ foi menor do que a média numérica de GPD do aleitamento (MOALLEM et al., 2006). A segunda razão é que $6 \mathrm{~L}$ também não teve a maior ingestão de concentrado, que exerce importante influência no desenvolvimento ruminal e no desenvolvimento pós-desmame (GREENWOOD et al. 1997), figurando portanto, de forma intermediária dentro das duas vertentes de desenvolvimento das bezerras em se tratando de nutrição, a saber, volume de leite e volume de concentrado na fase de aleitamento.

O GPD a um ano dos tratamentos variou entre 0,72 a 0,78 Kg / dia. Zanton e Heinrichs (2009) indicaram que o GPD de toda a fase de recria das novilhas deve variar entre 0,78 e $0,9 \mathrm{Kg} / \mathrm{dia} e$, que o valor de 0,8 $\mathrm{Kg}$ por dia de GPD seria o resultado de ganho de peso que otimizaria a produção de leite na primeira lactação e a produção de proteína do leite também na primeira lactação. Os resultados do presente trabalho apresentam valores menores de GPD a um ano, porém, se houver a continuidade da mensuração de ganho de peso das novilhas até a conclusão da recria por ocasião do primeiro parto, existe a possibilidade de que todos os tratamentos estejam dentro do que foi preconizado por Zanton e Heinrichs (2009).

\section{CONCLUSÃO}

Os dados avaliados neste estudo apontam que a concentração sérica de IgG não influenciou 0 peso ao nascimento e o ganho de peso das bezerras no primeiro ano de vida. $O$ peso ao nascimento não influenciou o ganho de peso independente dos protocolos de aleitamento utilizados. $\mathrm{Na}$ fase de aleitamento os maiores consumos de leite levaram aos maiores valores de ganho de peso diário das bezerras, no entanto, esse resultado não se perdurou após um ano de idade. Dentre os protocolos de aleitamento testados, ingestão de 4 litros de leite e ingestão $a d$ libitum apresentaram os melhores desempenhos em ganho de peso a um ano de idade.

\section{REFERÊNCIAS}

AMERI, M.; WILKERSON, M. Comparison of two commercial radial immunodiffusion assays for detection of bovine immunoglobulin $\mathrm{G}$ in newborn calves. Journal of Veterinary Diagnostic Investigation, v. 20, p.333-336, 2008.

APPLEBY, M. C.; WEARY, D. M.; CHUA, B. Performance and feeding behaviour of calves on adlibitummilk from artificial teats. Applied Animal Behaviour Science, v.74, p.191-201, 2001.

BALDWIN, R. L. V. I. et al. Rumen development, intestinal growth and hepatic metabolism in the pre- and postweaning ruminant. Journal of Dairy Science, v.87, p. E55-E65, 2004.

BALLOU, M.A.: Immune responses of Holstein and Jersey calves during the preweaning and immediate postweaned periods when fed varying 
planes of milk replacer. Journal of Dairy Science, v.95, p.7319-7330, 2012.

BORDERAS, T. F.; PASSILLÉ, A. M. B.; RUSHEN J. Feeding behavior of calves fed small or large amounts of milk. Journal of Dairy Science, v. 92, p. 2843-2852, 2009.

DACCARETT, M. G. et al. Performance of Holstein heifers fed $100 \%$ or more of National Research Council requirements. Journal of Dairy Science., Champaign, v.76, p. 606, 1993.

FOOTE, M. R. et al. Effects of Age and Nutrition on Expression of CD25, CD44, and L-Selectin (CD62L) on T-cells from Neonatal Calves. Journal of Dairy Science, v.88, p. 2718-2729, 2005.

FREITAS, J. A. et al. Influency of different Holstein heifers growth rates on milk production and age at first calving. Revista Brasileira de Ciências Veterinárias, v.17, n.2, p. 55-58, 2010.

GUILLOTEAU, R. et al. Enzime potentialities of the abomasums anda pancreas of the calf. Reprodution Nutrition Development. v.25, p. 481493, 1985.

GOFF, J.P. Major advances in our understanding of nutritional influences on bovine health. Journal of Dairy Science, v.89, p.1292-1301, 2006.

GREENWOOD, R. H.; MORRILL, J. L.; TITGEMEYER, E. C. Using dry feed intake as a percentage of initial body weight as a weaning criterion. Journal of Dairy Science, v. 80, p. 25422546, 1997.

HILL, T. M. et al. Effect of milk replacer program on digestion of nutrients in dairy calves. Journal of Dairy Science, v. 93, p. 1105-1115. 2010.

KHAN, M. A.; LEE, H. J.; LEE, H. S. Pre and post weaning performance of Holstein female calves fed milk through step-down and conventional methods. Journal of Dairy Science, v. 90, p. 876885, 2007.

KRISTENSEN, N. B.; SEHESTED, J.; JENSEN, $S$. K. Effect of milk allowance on concentrate intake, ruminal environment, and ruminal development in milk fed Holstein calves. Journal of Dairy Science, v. 90, p. 4346-4355, 2007.

LOPES, M. A.; VIEIRA, F. P. Criação de bezerros leiteiros. São Paulo: Funep, 1998.

MENDONSA, K. M. Factors affecting passive transfer in neonatal calves. San Luiz Obispo: California Polytechnic State University; Dairy Science Department, 2011. Disponível em: $<$ http://digitalcommons.calpoly.edu/cgi/viewconte nt.cgi ?article $=1048 \&$ context=dscisp $>$. Acesso em: 10 set. 2013.
MOALLEM, U. al. Effects of feeding ad-lib fresh milk or milk replacer during nursing and added protein at pre-puberty period to Holstein heifers on growth rates and production during the first lactation. Journal of Dairy Science, v.89, p.32, 2006.

NONNECKE, B.J. et al. Composition and functional capacity of blood mononuclear leukocyte populations from neonatal calves on standard and intensified milk replacer diets. Journal of Dairy Science, v.86, p. 3592-3604, 2003.

QUIGLEY, J. D.; DREWRY, J. J. Nutrient and immunity transfer from cow to calf pre- and postcalving. Journal of Dairy Science, v. 81, p. 27792790, 1998.

ROBISON, J. D.; STOTT, G. H.; DENISE, S. K. Effects of passive immunity on growth and survival in the dairy heifer. Journal of Dairy Science, v. 71, p. 1283-1287, 1988.

ROTH, B. A. et al. Influence of weaning method on health status and rumen development in dairy calves. Journal of Dairy Science, v. 92, p. 645656, 2009.

TIZARD, I. R.; Imunologia Veterinária: uma introdução. São Paulo: Rocca, São Paulo SP. 545p, 1998.

TYLER, J. W. et al. Evaluation of 3 assays for failure of assive transfer in calves. Journal of Veterinary International Medicine, v. 10, p. 304307, 1996.

VAN AMBURG, M. Calf growth and development: New requirements and implications for future performance. IN: SOUTHWEAST NUTRITION AND MANEGEMENT CONFERENCE, 18., 2003, Tucson. Proceedings... Tucson: University of Arizona, 2003. p. 1-13.

ZANTON, G. I.; HEINRICHS, G. I. Limit-Feeding with altered Forageto-Concentrate Levels in Dairy Heifer Diets.A Review. The Professional Animal Scientist, v. 25, p. 393-403, 2009. 